\title{
Revista Brasileira de Enfermagem REBEn \\ Uma prática educativa de sensibilização quanto à exposição a radiação ionizante com profissionais de saúde
}

\author{
An educative practice of sensitization to ionizing radiation \\ exposition with health professionals
}

Una práctica educativa de sensibización a la exposición a radiación ionizante con profesionales de salud

\section{Rita de Cássia Flôr}

Aluna do Curso de Mestrado em Enfermagem do Programa de Pós Graduação em Enfermagem da Universidade Federal de Santa Catarina - UFSC. Professora do Centro Federal de Educação Tecnológica de Santa Catarina -

CEFET/SC.

Endereco para contato:

Rua Felipe Schmidt, 755 apt. 803

CEP: 88010-002 - Florianópolis

flor@newsite.com.br

flor@cefetsc.edu.br

Ana Lúcia Cardoso Kirchhof

Professora Adjunto do Departamento de Enfermagem da Universidade Federal de Santa

Catarina. Membro do Grupo de Pesquisa em

Saúde, Trabalho e Cidadania - PRAXIS.

\section{RESUMO}

Este estudo apresenta uma prática assistencial de enfermagem que teve como objetivo a sensibilização dos profissionais de saúde na unidade de terapia neonatal quanto à exposição à radiação ionizante, visando à otimização da proteção radiológica. O Modelo Operário Italiano (MOI) foi o referencial teórico e metodológico norteador dessa prática, desenvolvida em um hospital público de Florianópolis-SC com 12 participantes. Os resultados demonstraram que os profissionais de saúde expõem-se às radiações ionizantes, principalmente por desconhecerem as recomendações previstas na legislação.

Descritores: Radiação ionizante; Riscos ocupacionais; Programa de prevenção de riscos no ambiente de trabalho; Cuidados intensivos; Neonatologia

\section{ABSTRACT}

This study present a nursing care practice whose objective is to sensitize health professionals of neonatal intensive care unit about the risk of exposition to ionizing radiation, aiming to optimize the radiological protection. The Operative Italian Model (OIM) was the main theoretical and methodological reference which guided this practice, carried out with twelve participants in a public hospital in Florianópolis-SC, Brazil. The results demonstrated that health professionals are exposed to ionizing radiation, especially for not being aware of the recommendations already included in the legislation.

Descriptors: Radiation, ionizing; Occupational risks; Program of risk prevention on working environment; Intensive care; Neonatal.

\section{RESUMEN}

Se trata de una práctica asistencial de enfermería que tuvo por objetivo la sensibilización de los profesionales de salud de la unidad de terapia intensiva neonatal en lo referente a la exposición a radiación ionizante, procurando la optimización de la protección radiológica. El Modelo Obreiro Italiano (MOl) fue el referente teórico y metodológico orientador de dicha práctica, realizada con 12 participantes en un hospital público de Florianópolis/ SC. Los resultados demuestran que los profesionales de salud se exponen a radiaciones ionizantes principalmente por desconocer las recomendaciones previstas en la legislación.

Descriptores: Radiación ionizante; Riesgos laborales; Programa de prevención de riesgos en el ambiente de trabajo; Cuidados intensivos; Neonatología.

Flôr RC, Kirchhof ALC. Uma prática educativa de sensibilização quanto à exposição a radiação ionizante com profissionais de saúde. Rev Bras Enferm 2006 maio-jun; 59(3): 274-8.

\section{INTRODUÇÃO}

Radiação ionizante é o termo usado para descrever o transporte de energia, tanto na forma de ondas eletromagnéticas como na de partículas subatômicas, capazes de causar ionização da matéria. Quando a radiação ionizante passa através da matéria, confere energia por excitações ou ionizações. Os efeitos da radiação dependem, sobretudo, da quantidade e da qualidade da radiação incidente e da natureza do material com a qual está interagindo. Oliveira e Mota ${ }^{(1)}$ classificam as radiações ionizantes em "diretamente ionizante" e "indiretamente ionizante". São consideradas diretamente ionizantes, todas as partículas carregadas (alfa, beta, prótons, íons pesados...), pois produzem ionizações ao perder energia. Nas radiações indiretamente ionizantes (raios X, gama e neutros), a energia é transmitida para a matéria por meio das ionizações produzidas pelas partículas carregadas secundárias, geradas pela radiação primária.

Os raios $X$, radiações ionizantes considerados neste estudo, são um tipo de radiação semelhante à luz, mas invisíveis e com energia suficiente para atravessar corpos opacos. São produzidos pelos
Submissão: 02/05/2005

Aprovação: 05/04/2006 
elétrons que se movem do catodo para o anodo dentro do tubo de raios $X$, acelerados por uma alta tensão [...], com produção de fótons na ordem de $1 \%$ e aumento da temperatura do anodo $99 \%$. Esses fótons constituem a radiação que será utilizada para produzir a imagem radiográfica ${ }^{(2)}$. A radiação é produzida no anodo para todas as direções. Por isso, o tubo é colocado dentro de uma calota protetora revestida de chumbo. Essa radiação que sai do tubo é denominada de radiação primária. Quando o feixe primário passa através da pessoa, ele é atenuado na medida em que os fótons vão interagindo com as estruturas internas do corpo, resultando em diferentes intensidades devido à absorção de feixe de raios X. Qualquer objeto (pessoa, cadeira, parede) atingido por essa radiação atua como um emissor de radiação, chamada de radiação secundária ou espalhada ${ }^{(1)}$.

As unidades de terapias intensivas adulto e neonatal, unidades de internações, centros cirúrgicos, unidades coronarianas, entre outras, convivem freqüentemente com exposições à radiação ionizante proveniente dos equipamentos radiológicos portáteis. Esses equipamentos são utilizados para realizar os exames de raios $X$ no leito quando da impossibilidade do usuário ser transferido para uma instalação com equipamento fixo.

A Portaria $453 / 1998^{(3)}$, em seu item 4.27 , normatiza que a realização de exames radiológicos com equipamentos móveis em leitos hospitalares ou em ambientes coletivos de internação [...] somente será permitida quando for impossível ou clinicamente inaceitável transferir o usuário para uma instalação com equipamento fixo. Neste caso, deve ser adotada uma das seguintes medidas:

Os demais usuários que não puderem ser removidos do ambiente devem ser protegidos da radiação espalhada por uma barreira protetora com, no mínimo, 0,5 mm equivalência de chumbo; ou, posicioná-los de modo que nenhuma parte do corpo esteja a menos de dois metros do cabeçote ou do receptor de imagem ${ }^{(3)}$.

Considerando os aspectos acima evidenciados, assim como detectando a necessidade de sensibilizar os profissionais de saúde, atuantes na unidade de terapia neonatal, quanto à presença dessa carga física no seu ambiente de trabalho, optou-se por realizar a prática assistencial proposta pelo Curso de Mestrado do Programa de Pós Graduação em Enfermagem da Universidade Federal de Santa Catarina sob a formulação da seguinte pergunta norteadora: como desenvolver o trabalho em saúde minimizando a exposição à radiação ionizante nos profissionais de saúde que trabalham na unidade de terapia neonatal?

$\mathrm{Na}$ busca pela resposta, procurou-se inicialmente embasamento, teórico que justificasse o porquê dessas exposições e qual contribuição se poderia apresentar a fim de minimizar essa carga física do ambiente, proveniente dos exames radiológicos, devido a impossibilidade de transferência dos recém-nascidos para uma instalação com equipamento fixo.

Assim sendo, esta prática assistencial de enfermagem foi delineada, tendo por objetivo implementar e avaliar uma prática educativa de sensibilização quanto à exposição à radiação ionizante, com os profissionais da unidade de terapia neonatal, visando à otimização da proteção radiológica.

O Modelo Operário Italiano (MOI) foi o referencial teórico e metodológico norteador desse estudo, além de outros conceitos necessários para a fundamentação dessa temática.

Este modelo é um método de geração do conhecimento para a ação, ou seja, a preocupação fundamental é transformar as condições de trabalho, com vistas ao bem-estar e à proteção da saúde dos trabalhadores, a partir do conhecimento detalhado do processo de trabalho. Facchini( ${ }^{(4)}$ ressalta que a participação dos trabalhadores no processo de geração de conhecimento é fundamental, pois sua experiência é uma fonte riquíssima de abordagem e de entendimento da realidade, desde que possibilite chegar à generalidade a partir das particularidades, ou seja, que haja um processo de teorização sobre os achados particulares. É um método qualitativo e valoriza sempre a participação dos trabalhadores nas questões relacionadas à sua saúde a partir do reconhecimento do seu saber e do seu papel estratégico para as mudanças necessárias no processo de trabalho.

Esse modelo apresenta quatro pressupostos básicos que constituem este referencial teórico, a saber: a valorização da experiência e subjetividade operária, o levantamento das informações por grupos homogêneos, a não delegação da produção do conhecimento e a validação consensual das informações ${ }^{(4)}$.

As cargas de trabalho são classificadas segundo sua natureza ou característica básica, de modo a facilitar sua identificação ou mediação no processo de adoecimento. Assim são classificadas em: cargas físicas, mecânicas, químicas, orgânicas e fisiológicas ${ }^{(5)}$. Considerando o objeto pesquisado, ou seja, a radiação ionizante, as cargas de trabalho mais evidenciadas foram as cargas físicas.

0 processo de trabalho configura-se de acordo com o contexto em que ele ocorre, de modo que seus componentes não podem ser considerados pré-estabelecidos, havendo a necessidade do pesquisador analisá-lo em seus elementos: objeto, instrumentos, produto e o trabalho em si ${ }^{\left({ }^{6}\right)}$. No caso da exposição à radiação ionizante entre os profissionais de saúde, a análise ocorre levando-se em conta a radiação como objeto de trabalho e enquanto parte das condições de trabalho, ao ser uma carga física de trabalho.

O conceito de exposição baseou-se na Portaria 453/1998(3) que a classifica a em: médica, normal, potencial e ocupacional. Para efeito desta prática, utilizaram-se os conceitos de exposição médica - que é a exposição a que são submetidos, clientes, em decorrência de exames ou tratamentos; indivíduos não ocupacionalmente expostos que voluntariamente ajudam a confortar ou conter clientes durante o procedimento radiológico [...] e exposição ocupacional - que é a exposição de um indivíduo em decorrência de seu trabalho em práticas autorizadas.

E, por fim, o conceito de prática de enfermagem que baseado no processo de trabalho educar da enfermagem, que pode voltar-se tanto para um indivíduo quanto para um grupo [...]. O campo prático desse processo de trabalho é cada dia maior tendo-se em vista a perspectiva de que um maior nível de qualificação da força de trabalho tem sido uma exigência do mercado e que, como trabalhadores, todos precisam dar atenção à sua saúde ${ }^{(7)}$.

\section{METODOLOGIA}

A prática assistencial foi realizada na unidade de terapia neonatal de um hospital público de Florianópolis-SC, no período de 10 de outubro a 30 de novembro de 2004, sob a forma de observações do trabalho em andamento, entrevistas para esclarecer dúvidas, análise documental e reuniões com o grupo homogêneo, num total de doze encontros.

Foram obedecidos os aspectos concernentes à Resolução de $\mathrm{N}^{\circ}$ 169 de 10 de outubro de 1996 que estabelece as diretrizes regulamentadoras em pesquisas envolvendo seres humanos ${ }^{(8)}$. Para garantir 0 anonimato os participantes da prática foram codificados com nomes dos elementos químicos radioativos tais como: Tecnécio (Tc), Amerício (am), Urânio (U), Rádio (Ra), Césio (Cs), Molibdênio (Mo), Tálio (Ti), Cobalto (Co), Gálio (Ga), lodo (I), Radônio (R) e Samário (Sm).

Na primeira visita feita à unidade hospitalar, foi explicada a razão da pesquisa e os profissionais de saúde da unidade de terapia neonatal, assim como os Técnicos em Radiologia foram convidados a participar do grupo homogêneo, o que foi prontamente aceito.

Posteriormente buscou-se conhecer como se dava a exposição à radiação ionizante na unidade, bem como ouvir a opinião dos trabalhadores de saúde acerca dos conhecimentos dessa carga física. Inicialmente, a coleta de informações foi feita por meio de observações, que 
é "o processo pelo qual a primeira e mais imediata função consiste em obter informações referentes ao fenômeno estudado, em função de um propósito planejado e organizado (...)"(9). A mesma autora alerta para 0 fato de que diferentes propósitos ou diferentes questões de investigação requerem diferentes estratégias de observação e também diferenças nos níveis de sistematização (...).

Assim, sistematizou-se acompanhamento do processo de trabalho das atividades do profissional Técnico em Radiologia no setor de neonatologia na aquisição de imagem radiológica dos recém-nascidos e, conseqüentemente, dos demais profissionais de saúde que ali já se encontravam. A observação dava-se coletivamente de modo que os profissionais não percebessem que estavam sendo observados. Dessa forma, garantiu-se a fidedignidade do processo, o qual envolvia exposição à radiação ionizante e a forma como os profissionais de saúde protegiam-se dessa carga física. Foram realizadas seis observações, sendo que as mesmas aconteciam deste a chegada do profissional Técnico em Radiologia à UTI neonatal com o equipamento móvel, até a finalização do procedimento. Os dados obtidos nas observações foram registrados e fotografados. Os registros foram organizados para posteriormente serem validados.

Para a realização das entrevistas, trabalhadores de saúde da unidade de terapia neonatal e os profissionais Técnicos em Radiologia foram convidados de forma aleatória, nos momentos de visita na unidade. Dentre os que aceitaram participar, procurou-se contemplar os profissionais Técnicos em Radiologia, Enfermeiras, Auxiliares e Técnicos de Enfermagem e Médicos. As entrevistas foram realizadas individualmente e coletivamente. Para Facchini(5), uma entrevista individual tem menor capacidade de captar informações precisas e complexas sobre 0 processo de trabalho que uma entrevista coletiva, na qual a própria discussão tem um poder de mobilização da consciência operária sobre os aspectos mais importantes do processo de trabalho.

Para a realização das entrevistas foi utilizado o método de entrevista informal. Partia-se da realidade vivenciada pelos profissionais de saúde, valorizando sempre o conhecimento e a subjetividade dos profissionais. Foram registradas palavras-chave ditas na entrevista as quais juntamente com os dados obtidos na observação foram, posteriormente, validados pelo grupo homogêneo, constituído pelos profissionais Técnicos em Radiologia, Médico, Enfermeiros, Técnicos em Enfermagem e Auxiliar em Enfermagem. Facchini(5) argumenta que na constituição desse grupo deve-se buscar a representatividade dos trabalhadores de diver-sas categorias funcionais e setores da instituição.

Os integrantes do grupo homogêneo socializaram suas idéias, suas experiências, suscitando discussões importantes em relação à exposição à radiação ionizante, buscando reflexões com base nos dados das observações, entrevistas e análise documental. Para impedir a variabilidade individual de opiniões, os resultados levantados foram validados consensualmente. Somente foram registradas as informações que o grupo homogêneo, em seu conjunto, reconheceu como corretas.

Por fim, as informações foram socializadas em um encontro realizado no anfiteatro da instituição pesquisada com duração de duas horas e
30 minutos. Contou com a adesão dos integrantes do grupo homogêneo, assim como de outros trabalhadores que compartilhavam condições de trabalho semelhante.

\section{RESULTADOS E DISCUSSÃO}

O quadro 1 descreve simplificadamente como se dá o processo de trabalho do profissional Técnico em Radiologia na aquisição da imagem radiológica dos recém-nascidos ( $\mathrm{RNs}$ ) na unidade de terapia neonatal.

Nesse processo de trabalho, puderam ser evidenciadas várias situações de exposição à radiação ionizante. Percebe-se que os profissionais de saúde encontram-se desprotegidos e até mesmo desinformados quanto aos cuidados mínimos de proteção radiológica ${ }^{(10)}$. Em algumas falas das entrevistas ficaram evidentes essas situações.

(...)] Trabalho há 17 anos aqui (...) Nunca ninguém disse que isto era errado. Descobri há um ano que tenho hipotireoidismo. Será que a radiação tem alguma coisa a ver com isso? Um dia falei para o técnico em radiologia que tinha hipotireoidismo e ele me disse, de agora em diante você deve ficar bem longe dos raios $X$ (...) (Cobalto).

(...) Não usamos avental porque não tem. Por isso corremos parar atrás do técnico. Sempre fizemos isso. Não tem protetor de tireóide, só tem um avental que o técnico usa. Todos os dias são realizados raios $X$ aqui (...) (Samário).

A unidade de neonatologia compreende duas salas de cuidados intermediários, duas salas de isolamento e uma unidade de terapia intensiva (UTI), totalizando 20 leitos. Destes, 10 são leitos de UTI.

A assistência de enfermagem, no cuidado intensivo, requer procedimentos bastante complexos, instrumentalizados pelas técnicas de enfermagem específicas para as diversas terapias. Ė mediada por equipamentos sofisticados, que tanto fazem o controle de disfunções biológicas como necessitam ser controlados, constituindo-se ora em instrumento, ora em objeto de trabalho(2).

A equipe de saúde de dessa unidade é composta por 38 profissionais distribuídos conforme mostra a tabela 1.

\section{Tabela 1. Distribuição dos profissionais por categoria. Florianópolis,} 2004.

\begin{tabular}{lcc}
\hline Profissionais & $\mathbf{n}$ & $\mathbf{\%}$ \\
\hline Enfermeiro & 3 & 7,9 \\
Técnico em Enfermagem & 11 & 29,1 \\
Técnico Administrativo & 2 & 5,2 \\
Auxiliar de Enfermagem & 21 & 55,1 \\
Agente de Serviços Gerais & 1 & 2,7 \\
\hline Total & $\mathbf{3 8}$ & $\mathbf{1 0 0 , 0}$ \\
\hline
\end{tabular}

Percebe-se que, na unidade, além dessas atividades inerentes ao processo de trabalho dos profissionais de saúde dessa unidade, são desenvolvidas diariamente atividades relacionadas com os exames de

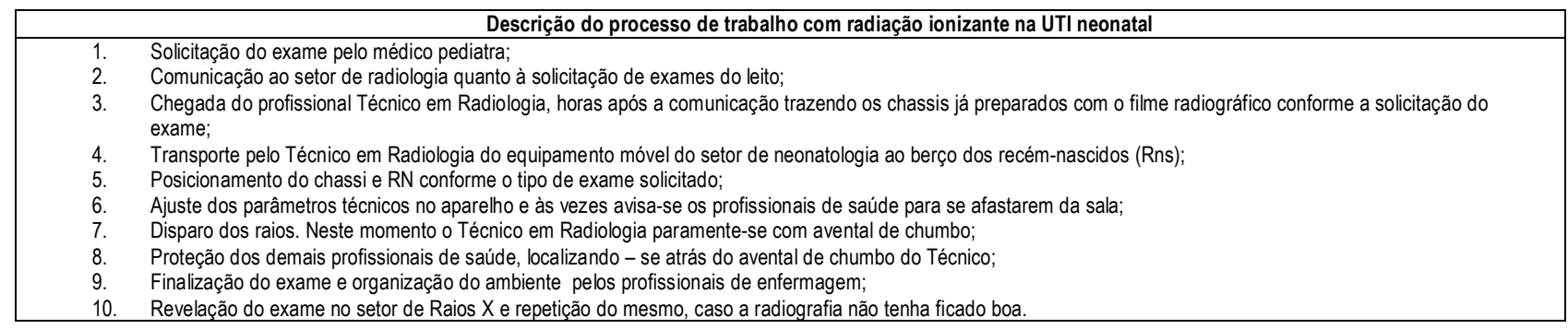

Quadro 1. Descrição simplificada do processo de trabalho na aquisição de raios X na UTI neonatal. Florianópolis, 2004. 
raios $\mathrm{X}$ no leito. Tais atividades envolvem contenção, conforto e apoio às atividades do profissional Técnico em Radiologia. Essas atividades foram evidenciadas nas falas como seguem:

(...) Às vezes estamos realizando procedimento nos Rns e não saímos com a chegada do aparelho de raios $X$, isto já é rotina, porque nunca ninguém falou nada. Eles ainda brincam o raio não faz curva, podem ficar atrás de mim (...) (Molibdênio).

(...) Trabalho há 17 anos aqui e já perdi a conta de quantos exames eu ajudei e sempre corro para trás do técnico. Nunca ninguém disse que isto estava errado (...) (Tálio).

Está evidente, que essa atividade de apoio ao procedimento radiológico na unidade neonatal merece atenção especial, principalmente no que tange à otimização da proteção radiológica. Tal atenção faz-se necessário, pois, a média de solicitação de exames no leito é de aproximadamente 10 exames por dia. Considerando esse contexto, esse dado torna-se preocupante. A falta de proteção adequada e de informação quanto a essa carga física presente em seu ambiente de trabalho foi evidenciada nos depoimentos dos sujeitos e na atitude demonstrada ao denotar o desconhecimento das formas de proteção, conforme falas transcritas:

(...) Trabalho há 17 anos aqui e já perdi a conta de quantos exames eu ajudei e sempre corro para trás do técnico. Nunca ninguém disse que isto era errado (...) (Gálio).

(...) Trabalho há 18 anos neste setor, e já perdi a conta da quantidade de exame que eu ajudei a fazer, pois alguns Rns precisam ser contidos e quem faz isso somos nós. Um RN que ficou internado a mais ou menos dois meses e meio chegou a fazer 59 radiografias. $A$ média dependendo do tempo de internação chega a 28 exames por $R N$. Não sei até que ponto a radiação tem efeito maléfico. Já existe algum estudo sobre isso?(...) (Urânio).

Por outro lado no relato dos Técnicos em Radiologia acerca dos princípios básicos de proteção radiológica fica evidente seu conhecimento sobre proteção os efeitos advindos das radiações ionizantes. Além disso, eles mostraram saber se proteger contra esses efeitos, embora quando se trata de prestar informações aos demais profissionais de saúde, que estão sob a sua responsabilidade, esse conhecimento é negligenciado. Mesmo assim, em seus relatos, fica evidente a preocupação com a saúde e segurança, principalmente com os profissionais, o que fica claro no seguinte depoimento:

(...) Preocupo-me com os profissionais de enfermagem em relação à radiação eu até aviso para eles saírem quando vou fazer os raios $X$, mas eles não dão muita bola. Muitas vezes ouvi algumas falarem. Eu já fui laqueada, não tem mais problema! Outras chegaram a me dizer, não vou ter mais filhos! Eu explico que não é bem assim (...) (Tecnécio).

Além da falta de proteção adequada e de informação quanto à carga física presente do ambiente de trabalho, outro aspecto interessante evidenciado na fala dos entrevistados é sua atitude descuidada quanto à presença dessa carga física em seu ambiente de trabalho. Mesmo sendo avisados para afastarem-se do ambiente, ignoraram o aviso e continuam seus trabalhos sem questionar. É o que testemunha um Técnico em Radiologia em seu depoimento:

(...) Quando pedimos para as pessoas aguardarem lá fora porque vamos realizar os raios $X$, eles respondem, já estou acostumada pode batê (...) (Amerício).
Embora tenha sido evidenciado esse descaso quanto à exposição à radiação ionizante por parte de alguns profissionais, também foram relatadas preocupações com os riscos dessa carga física. Alguns mostraram ciência de que, por mais invisível que seja, esse risco está presente naquele ambiente de trabalho, podendo levar a danos biológicos tardiamente:

(...) Preocupa-me, porque por mais que a gente não enxergue, o perigo existe. Agora não sentimos nada e depois o que nos acontecerá? (...) (Césio).

(...) A gente até sabe que não pode ficar na sala, mas muitas vezes estamos tão envolvidos com os Rns, que nem percebemos a presença do aparelho de raios- $X$, quando nos damos conta o técnico já disparou o raio (...) (Radio).

\section{CONCLUSÃO}

Levando em consideração as características do processo de trabalho em saúde, sobretudo do profissional Técnico em Radiologia e considerando as peculiaridades do processo de trabalho na unidade de terapia neonatal, envolvendo exposição à radiação ionizante, inicialmente encontraram-se alguns problemas na aplicabilidade da metodologia escolhida, principalmente no que tange à constituição dos grupos homogêneos.

A dificuldade de organizar esse grupo deu-se, essencialmente, devido à característica do processo de trabalho dos profissionais Técnicos em Radiologia, pois os mesmos possuem uma carga horária de quatro horas diárias e, além da sobrecarga de trabalho que lhes é imposta, ou seja, aproximadamente 60 incidências radiográficas por período, o mesmo ainda cumpre outras jornadas de trabalho em outras instituições. Assim, o único tempo disponível para os encontros era entre o processamento de uma película radiográfica e outra, no próprio setor de radiologia. Outro momento que fazia parte desses encontros era quando a unidade solicitava sua presença para realizar os exames no leito. Naquele momento, além de observar como se dava a realização de exames radiológicos nos recém-nascidos, também observavam-se os demais profissionais envolvidos no processo de trabalho.

Portanto, na constituição dos grupos homogêneos, mesmo priorizado os profissionais Técnicos em Radiologia, contou-se com pouca participação desses profissionais nas discussões, mesmo que contribuíssem quando solicitados .

A exposição à radiação ionizante na unidade pesquisada dava-se principalmente nas atividades de contenção, conforto e apoio às atividades do profissional técnico em radiologia quando da realização de exames nos recém-nascidos no leito. Tais atividades foram evidenciadas diariamente e validadas pelo grupo homogêneo consensualmente. Essa situação de exposição é preocupante, pois os profissionais de saúde, em geral, desconhecem os cuidados mínimos de proteção radiológica. Além do desconhecimento dos princípios básicos de proteção radiológica, também pode ser evidenciada a escassez dos equipamentos de proteção individual plumbíferos, assim como sua conservação, pois foram verificadas várias situações nas quais este equipamento encontrava-se dobrado em cima dos equipamentos móveis.

O estudo realizado por Silva ${ }^{(11)}$ ressalta a necessidade de se manter uma educação permanente com os profissionais que se expõem à radiação ionizante.

Nessa perspectiva, acredita-se que esta prática tenha atingido seu objetivo, sensibilizando os profissionais de saúde quanto aos possíveis efeitos da carga física de radiação ionizante no ambiente de trabalho, assim como buscando mobilizá-los para implementação de uma ação transformadora das condições de trabalho, com vistas à otimização da proteção radiológica. 


\section{REFERÊNCIAS}

1. Oliveira SV, Mota HC. Notas do Curso básico de licenciamento e fiscalização em radiologia médica e odontológica. Rio de Janeiro (RJ): IRD/CNEN; 1999.

2. Mota HC. Proteção radiológica e Controle de Qualidade em Radiologia. Rio de Janeiro (RJ): IRD/CNEN; 1994.

3. Brasil. Portaria $453,1^{\circ}$ de junho de 1998. Diretrizes de Proteção Radiológica em Radiodiagnóstico Médico e Odontológico. Brasilia: Diário Oficial da União; 1998.

4. Facchini LA, Weiderpass E, Tomasi E. Modelo Operário e percepção de riscos ocupacionais e ambientais: o uso exemplar de um estudo descritivo. Rev Saúde Pub 1991; 25: 394-400.

5. Facchini LA. Uma contribuição da epidemiologia: o modelo da determinação social aplicado à saúde do trabalhador. In: Facchini LA. Isto é trabalho de gente? Vida, doença e trabalho no Brasil. São Paulo (SP): Vozes; 1994. p. 179-81.

6. Marx C. El capital: crítica de la economia política. La Habana (CUB):
Ciencias Sociales; 1986

7. Kirchhof ALC. O trabalho da enfermagem: análise e perspectivas. Rev Bras Enferm 2003; 56(6): 669-73.

8. Conselho Nacional de Saúde. Diretrizes Sobre Pesquisa em Seres Humanos. Brasília (DF): CNS; 1996.

9. Trentini M, Paim L. Pesquisa em enfermagem: uma modalidade convergente-assistencial. Florianópolis (SC): Ed. UFSC; 2004.

10. Caretta R, Belei RA, Haddad MCL, Bazoni E. Conhecimento da equipe de saúde sobre os efeitos e os meios de proteção dos raios X. Acta Paul Enferm 1998; 11(2): 47-55.

11. Silva AL. Estudo exploratório de conhecimento dos circulantes de sala de operação sobre radioproteção em centro cirúrgico: subsidio para elaboração de recomendações práticas. In: Anais do Congresso Brasileiro de Enfermagem em Centro Cirúrgico. São Paulo (SP); 1995. São Paulo (SP): SOBECC; 1995. p. 57-60. 